\title{
Algumas notas para a salvação do mundo
}

\author{
Rosa Maria Martelo \\ Universidade do Porto - ILC
}

Resumo: Que mundo ou mundos temos em mente quando falamos de salvar o mundo? E a que espécie de salvamento podemos aspirar? Considerando que tanto uma percepção dualista da relação entre ser humano e natureza quanto a aceitação de uma condição de excepcionalidade do humano no plano ontológico dificultam o urgente reequilíbrio ecológico de que precisamos, procura-se cotejar algumas propostas para o recentramento do nosso lugar no mundo.

Palavras-chave: mundo, salvação, Antropoceno, Capitaloceno, respiração, inspiração

Abstract: What world or worlds do we have in mind when we talk about saving the world? And what kind of salvation can we hope for? The dualistic perception of the relationship between humankind and nature as well as the acceptance of an ontological exceptionality of the humankind make more difficult the struggle for an ecological balance. This article aims at articulating some proposals for the recentering of the human species' place in the world.

Keywords: world, salvation, Anthropocene, Capitalocene, breathing, inspiration

Tocam-se o fim e o princípio:

FIAT LUX outra vez.

Murilo Mendes

Ao dar início ao ciclo de Seminários da Salvação do Mundo, Pedro Eiras começou por sublinhar o carácter polissémico de palavras como salvação e salvar, que podem revestir-se de sentidos muito diversos, ou mesmo inconciliáveis. A título de exemplo, 
lembrou as profundas diferenças que separam a ideia de salvar vidas da ideia de salvar almas, a primeira centrada na urgência, a segunda dirigida a um tempo fora do tempo. Naturalmente, seria possível constatar algo de muito semelhante também no que diz respeito à polissemia da palavra mundo. Em que mundo estamos a pensar quando falamos da salvação do mundo? Vivemos num mundo de mundos caracterizado por uma grande heterogeneidade e complexidade, pelo que talvez seja preciso começarmos por explicitar os mundos que cada um de nós tem em mente ao participar nestes seminários.

Pela minha parte, gostaria de partir da definição formulada por Eduardo Viveiros de Castro na notável conferência a que deu o título de "A revolução faz o bom tempo", na qual entende por mundo "o conjunto aberto e variável dos outros entes pelos quais passa a humanidade de referência para poder voltar a si, para poder olhar para si” (2014: 6.10m).' No período em que vivemos, esse conjunto aberto e variável não pode ser isolado dos efeitos que sobre nós produz a idade geológica que tem vindo a ser designada por Antropoceno, e na qual, independentemente do momento em que Ihe situemos a exacta origem (questão ainda polémica), a presença humana já interferiu no devir geológico do planeta de forma notória e apenas comparável com a de fenómenos tão extremos quanto o vulcanismo. Hoje, falarmos da salvação do mundo não pode ser muito diferente de falarmos do reequilíbrio ecológico de um planeta a que chamamos Terra, o qual passaria muito bem sem nome, provavelmente - e sem nós, humanos seres nomeadores de todas as coisas vivas e mortas, possíveis e impossíveis.

Sem nós, seres humanos, sem a relação que mantemos uns com os outros (nisto se incluindo os mortos que sobre nós fizeram impender desejos, escolhas, acertos, erros e desacertos) e com todos os outros entes, não faria sentido falar-se de mundo. Mas sem os outros seres, do maior ao menor, também não. A salvação do mundo é, pois, uma possibilidade que se coloca entre todos os seres à face da Terra, entre nós e as condições envolvidas na nossa existência relacional com todos os seres; ou melhor, entre nós e todas as condições da nossa existência relacional, passe o pleonasmo pois em última análise não temos outra existência que não essa. É, aliás, esse o motivo pelo qual me foi difícil responder ao repto deste ciclo dedicado à salvação do mundo. Ver à nossa volta tantos sinais de uma aceleração, inexorável no sentido da destruição já não reversível - apenas minorável - do mundo em que vivemos não pode deixar de ser paralisante. Mesmo se um dos traços distintivos do nosso tempo é a aceleração. Mas dir-se-ia que estamos paralisados pela aceleração precisamente, pela cegueira que ela produz, com a ressalva de que os seres humanos não formam de modo algum uma categoria homogénea; e não estamos todos paralisados da mesma forma nem pelas mesmas razões. Fazem, por isso, todo o sentido as reservas colocadas por alguns ao termo Antropoceno, na medida em que este atribui uma amplitude antropológica geral aos efeitos de uma visão do mundo que, de facto, apenas uma parte da humanidade 
agencia de modo directo. Nesse sentido, o termo Capitaloceno, contraposto por Jason W. Moore (2016) e Donna Haraway (2012; ver também 2015: 263, nota 6), pode ser mais exacto, ao destacar desde logo aqueles que são os protagonistas activos do desequilíbrio ecológico em curso.

Acresce que, apesar de nada ter de negativo à partida, a própria ideia de salvação já demonstrou não ser isenta de perigo. Critérios religiosos e ideológicos de salvação (da alma, da pátria, de certos quadros de valores - de um determinado “mundo", em suma) permitiram e continuam a permitir a perseguição, o assassínio em larga escala, o terrorismo, a tortura, o genocídio, a deportação e a “reeducação", formas tremendas de devastação. Grandes certezas acerca da salvação do mundo: é preciso desconfiar do que nos podem trazer, sempre. A história demonstra à saciedade que é fácil transformarem-se em instrumentos de intolerância, perseguição e destruição.

$*$

Só a um nível superficial poderá, então, o tema deste ciclo opor-se ao do ciclo anterior, dedicado ao fim do mundo. Em conjunto, os dois temas formam o verso e o reverso da mesma grande questão: a nossa sobrevivência e a de muitas outras espécies, os riscos que todos corremos actualmente devido ao grau de destruição que o desenvolvimento do capitalismo global infligiu e está a infligir ao equilíbrio ecológico do planeta. E o tempo é pouco porque a velocidade atingida pela Grande Aceleração que tem lugar desde meados do século XX capacitou-nos para uma eficácia tal na exploração de recursos finitos que, a continuarmos assim, estaremos condenados à extinção juntamente com muitas outras espécies. Lamentavelmente o impulso extractivista não parece refreável, e tudo leva a recear que o ritmo de amanhã seja ainda mais rápido que o de hoje.

*

O que podemos fazer? Vivemos num mundo "agilizado", “optimizado”, no qual todos os segundos contam. Somos lançados para a frente pelas circunstâncias do dia-a-dia e temos muito pouco tempo para avaliar as implicações dos passos que damos. Mas precisamos certamente de uma nova maneira de pensar e viver o tempo. De forma mais ou menos intuitiva, sentimos que há uma relação entre a ditadura exercida pela sobrevalorização do trabalho nas sociedades hiperindustrializadas e o desconforto existencial do nosso quotidiano, no qual, como mostrou Byung Chul-Han em O Aroma do Tempo - Um ensaio filosófico sobre a arte da demora (2016), o tempo sofre uma constante fragmentação, devido à ausência do ócio e da vida contemplativa, deixando-nos a vogar na ausência de sentido.

$\varepsilon$ Se Parássemos de Sobreviver? - perguntava André Barata, no seu Pequeno livro para pensar e agir contra a ditadura do tempo (2018). E essa é por certo uma pergunta a fazer em prol da salvação do (nosso) mundo. André Barata argumenta que 
o gesto mais revolucionário dos nossos dias é o de “desacelerar, parar”, sustentando que precisamos, antes de mais, de tomar consciência do facto de a ética protestante ter criado condições para "uma moralização da poupança, da eficiência, da acumulação e da racionalidade instrumental, em que quase tudo é meio e quase nada é fim em si mesmo" (2018: 102). Em última análise, defende o filósofo - que neste ponto segue as conhecidas teses de Max Weber -, é na ética protestante que radicam os pressupostos tratados ao longo do seu livro como condicionantes do nosso modo de encarar "o trabalho, o rendimento, a política e a economia, a realização e a necessidade, o viver e o sobreviver" (idem: 103). Para André Barata, na esteira de Hartmut Rosa, a aceleração do tempo social liga-se à história da modernidade, ou seja, a actual “industrialização do próprio tempo" teve origem na industrialização humana e no tempo industrial (idem: 102).

André Barata recorda que, hoje, a aceleração do tempo vai-nos levando ao esquecimento das maneiras de parar, transformando-nos em eternos sobreviventes sem uma verdadeira vida. E argumenta que, para iludir a ausência de tempo pessoal, as nossas vivências transformam-se sistematicamente em extimidade. Barata cita neste ponto Serge Tisseron, que, em L'Intimité surexposée (2007), usou este termo lacaniano por oposição a intimidade. A quem não consegue desacelerar, a extimidade proporcionaria uma ilusão de sentido, se bem que um sentido em constante obsolescência, do qual emana um sentimento de pertença ao mundo que é experimentado em constante risco de perda (o exemplo são aqui obviamente as redes sociais) (cf. Barata 2018: 104-105), já que a extimidade exige a repetição constante da exterioridade, da manifestação do vivido, tantas vezes experimentado já à partida sob a forma de relato, registo antecipado e representação antecipada: de desajuste no tempo, em suma. A extimidade seria, então, uma condição de exterioridade do sujeito relativamente ao seu próprio mundo, um viver narcisicamente, diferidamente, sob a forma de imagem multiplicada, ou reflexo.

$*$

Há algo de irrespirável nesta experiência do tempo que as imagens da extimidade lançam inexoravelmente para diante. É uma experiência precária, que se resume em pura exterioridade, sem intimidade que a sustente. E é por isso de um modo contrapontístico que passarei a lembrar a leitura do nosso estar-no-mundo sob a perspectiva da imersão, tal como é formulada por Emanuelle Coccia em A Vida das Plantas (2013). Coccia descreve a sua filosofia como uma metafísica dos fluidos, e a tese central deste livro assenta na constatação biológica de que "[n]unca poderemos ficar materialmente separados da matéria do mundo", porquanto "todo o ser vivo se constrói a partir dessa mesma matéria que desenha as montanhas e as nuvens. A imersão é uma coincidência material que começa sob a nossa pele", lembra Coccia, e continua: "Ser-no-mundo significa, necessariamente, fazer mundo: qualquer actividade dos 
vivos é um acto de design na carne viva do mundo" (idem: 68). Assim, “[a] imersão é uma relação mais profunda do que a acção e a consciência - ela situa-se aquém tanto da práxis como do pensamento" (ibid.). E daí a noção que propõe, de "metafísica dos fluidos”. "O mundo”, afirma Coccia, "não é uma entidade autónoma e independente da vida, é a natureza fluida de todo o meio: clima, atmosfera. (...) Não é um espaço: é um corpo subtil, transparente, mal percebido pelo toque e pela vista” (idem: 77). Ou seja, o mundo é a atmosfera, literalmente; e também é uma atmosfera, quer dizer, também é aquele mundo em que estamos imersos. 0 que respiramos e o que nos respira:

\begin{abstract}
A respiração não se limita à actividade do vivo: ela define igualmente, e sobretudo, a consistência do mundo. 0 espaço que ela traça coincide com os limites do mundo de que podemos ter experiência. Chegamos onde chega a nossa respiração. Inversamente, um mundo sem respiração não seria mais do que um amontoado confuso de objectos em decomposição. (idem: 87)
\end{abstract}

Daí a conclusão de Coccia: “O mundo é respiração e tudo o que nele existe, existe como tal. A existência do mundo não é um facto de ordem lógica: é uma questão pneumatológica” (ibidem). Ou, dito de outro modo: “A atmosfera não é alguma coisa que tenha vindo juntar-se ao mundo: ela é o mundo enquanto realidade da mistura no interior da qual tudo respira" (idem: 95). É nessa medida que poderemos entender a atmosfera em que vivemos mergulhados também como "um facto cultural" (idem: 97). Dito de outro modo ainda: "O mundo não é um lugar: é o estado de imersão de todas as coisas em todas as outras coisas, a mistura que derruba instantaneamente a relação de inerência topológica" (idem: 99). Fluidos, influências, afluências: "relações - ligações”, como bem viu Mallarmé ao reflectir sobre as homologias entre o discurso poético e o mundo (Mallarmé apud Scherer 1977: 43).

Eduardo Viveiros de Castro também põe em causa a relação opositiva expressa no par natureza/cultura ao propor a noção de perspectivismo indígena para descrever a relação entre humanos e extra-humanos no pensamento ameríndio. E mostra que, nas culturas ameríndias, "os animais são gente”, ou foram gente, "no seu departamento”, tal como podem ser gente as pedras, as montanhas. Para Viveiros de Castro, esta espécie singular de antropomorfismo contrapõe-se ao antropocentrismo, isto é, ao entendimento do ser humano como “estado de excepção ontológico”, e tem muito a ensinar-nos por causa disso mesmo:

O mandato da antropologia é dissolver o homem, já dizia Lévi-Strauss. "Dissolver o homem" não é afirmar que o homem não existe, mas que o homem enquanto estado de exceção ontológico não existe, ele é uma ilegitimidade cósmica ambulante. É preciso 
aprender a existir como se esse homem não existisse, pois o risco que corremos hoje é de deixar de existir empiricamente e ponto. Nós estamos nos suicidando como espécie. Na medida em que ela mostra a existência de outras formas de existir como ser humano, a antropologia permite perceber que o caminho que os ocidentais estão seguindo não é [o] único possível. E que portanto, há esperança; se não no futuro, há esperança no passado. 0 que já é alguma coisa... (Castro 2014: 162)

Ora, compreender que o nosso mundo se define pela condição imersiva de que fala Coccia equivale a pôr em causa o estado de excepção ontológico denunciado por Viveiros de Castro; e supõe que amplamente (e não apenas excepcionalmente, singularmente) tomemos consciência de quanto "a respiração define a consciência do mundo”, na medida em que todos, sem excepção, somos seres cooperativos, dependentes de muitos outros, humanos e não-humanos: essa é a atmosfera em que estamos imersos, é esse o ar que respiramos. E a respiração tem uma particularidade: requer um ritmo. Fora do qual ninguém sobrevive. E aqui, a poesia, com as suas muitas narrativas do que é a inspiração, talvez possa ajudar no entendimento desta tarefa que nos envolve a todos: salvar o mundo, isto é, quebrar o processo de destruição a que chegámos, parar a tempo, reduzir a aceleração do tempo em que temos vindo a viver.

*

Dêmos então um passo atrás para recordar Paris em meados do século XIX. A relação ambivalente da poesia de Charles Baudelaire com a cidade pode revelar-se aqui sintomática, pois, como bem viu Walter Benjamin, Baudelaire teve uma percepção muito clara de que o capitalismo, com a sua lógica de acumulação, tinha vindo alterar definitivamente a nossa relação com a natureza. Por isso, o fascínio de Baudelaire pela cidade de Paris atinha-se aos que permaneciam nas margens de um progresso que, a vários títulos, o poeta adivinhava problemático. "Farol obscuro" - eis como Baudelaire descreveu o progresso técnico que fazia o orgulho dos seus contemporâneos (1976: 580). Do mesmo lado anti-burguês da experiência cidadina, Baudelaire unia o apache, os cães vadios e o poeta, isto é, aqueles que deixariam de ter lugar no mundo nascente - por muito que esse mundo também o fascinasse (e a beleza cosmopolita, requintadamente artificializada, fascinava-o em absoluto, como sabemos). Por isso, o olhar alegorista de Baudelaire perscruta uma ausência em tudo quanto vê. Walter Benjamin chamou a atenção para a importância das velhas torres sineiras na cidade descrita por Baudelaire, explicando que elas marcam o que resta de um mundo humano integrado na natureza. Em Portugal, Fernando Pessoa surpreendeu, pelo olhar de Alberto Caeiro, exactamente a mesma nostalgia num coetâneo de Baudelaire, Cesário Verde. Por certo um dos maiores leitores que o autor de As Flores do Mal alguma vez teve. 
Ao entardecer, debruçado pela janela,

E sabendo de soslaio que há campos em frente,

Leio até me arderem os olhos

O livro de Cesário Verde.

Que pena que tenho dele! Ele era um camponês

Que andava preso em liberdade pela cidade.

Mas o modo como olhava para as casas,

E o modo como reparava nas ruas,

E a maneira como dava pelas pessoas,

É o de quem olha para árvores,

E de quem desce os olhos pela estrada por onde vai andando

E anda a reparar nas flores que há pelos campos...

Por isso ele tinha aquela grande tristeza

Que ele nunca disse bem que tinha,

Mas andava na cidade como quem anda no campo

E triste como esmagar flores em livros

E pôr plantas em jarros... (Pessoa 200ı: 26)

“Aquela grande tristeza” que Caeiro reconhece em Cesário, o cantor de uma Lisboa que não hesitara em descrever, em carta ao Jornal de Viagens, como "um cadáver de cidade" (1880: 27), não andará por certo longe da nostalgia alegorista que Benjamin surpreendeu na escrita de Baudelaire, mais concretamente na pessoa do flâneur e na sua condição de mercadoria que ainda não se reconhece enquanto tal, ou seja, na sua condição de recém-chegado actor a uma sociedade gerida pela lógica do capital:

Pergunte-se a qualquer bom Francês que todos os dias lê, na sua loja, o jornal o que entende ele por progresso, e responderá que é o vapor, a electricidade e a iluminação a gás, esses milagres desconhecidos dos Romanos, acrescentando que tais descobertas inteiramente testemunham a nossa superioridade sobre os antigos; tal é a densidade das trevas nesse cérebro infeliz, e tal é o modo como as coisas de ordem material e espiritual aí se encontram bizarramente confundidas! (Baudelaire 1976: 580; trad. minha)

Esta “superioridade” técnica (cujas vantagens não se pretende aqui minimizar) merece a Baudelaire um desdém que poderíamos aproximar das críticas que, na actualidade, Davi Kopenawa, reconhecido activista e xamã yanomami, tem dirigido aos Brancos, aqueles que designa por Povo da Mercadoria. No prefácio da edição brasileira do livro que, a pedido de Kopenawa, o antropólogo Bruce Albert extraiu de muitas horas de conversa entre os dois, Viveiros de Castro faz o ponto da situação que vivemos a nível mundial, e sintetiza o ponto de vista yanomami: 
Neste momento, assistimos a uma mudança do equilíbrio termodinâmico global sem precedentes nos últimos II mil anos da história do planeta, e, associada a ela, a uma inquietação geopolítica inédita na história humana - se não em intensidade (ainda), certamente em extensão, na medida em que ela afeta literalmente 'todo (o) mundo'. Neste momento, portanto, nada mais apropriado que venha dos cafundós do mundo, dessa Amazônia indígena que ainda vai resistindo, mesmo combalida, a sucessivos assaltos; que venha, então, dos Yanomami, uma mensagem, uma profecia, um recado da mata alertando para a traição que estamos cometendo contra nossos conterrâneos - nossos co-terranos, nossos co-viventes -, assim como contra as próximas gerações humanas; contra nós mesmos, portanto. 0 que lemos em A queda do céu é a primeira tentativa sistemática de "antropologia simétrica”, ou "contra-antropologia”, do Antropoceno, a época geológica atual que, na opinião crescentemente consensual dos especialistas, sucedeu ao Holoceno, e na qual os efeitos da atividade humana - entenda-se, a economia industrial baseada na energia fóssil e no consumo exponencialmente crescente de espaço, tempo e matériasprimas - adquiriram a dimensão de uma força física dominante no planeta, a par do vulcanismo e dos movimentos tectônicos. Ao mesmo tempo uma explicação do mundo segundo outra cosmologia e uma caracterização dos Brancos segundo outra antropologia (uma contra-antropologia), A queda do céu entrelaça esses dois fios expositivos para chegar à conclusão de uma iminência da destruição do mundo, levada a cabo pela civilização que se julga a delícia do gênero humano - essa gente que, liberta de toda 'superstição retrógrada' e de todo ‘animismo primitivo', só jura pela santíssima trindade do Estado, do Mercado e da Ciência, respectivamente o Pai, o Filho e o Espírito Santo da teologia modernista. (Castro 2015: 23-24)

Para Davi Kopenawa, representante de um povo dizimado por sucessivas epidemias propagadas por missionários em empresas “salvadoras”, um povo cada vez mais acossado por garimpeiros, os Brancos são o Povo da Mercadoria, os Comedores de Terra, esventradores de montanhas em busca do ouro, apaixonados por coisas, como se essas coisas fossem a sua namorada. E este é um olhar de fora, descentrado relativamente à lógica do capital, a merecer a nossa atenção.

Voltando à poesia, parece haver uma relação a observar entre o desconforto expresso por Baudelaire no momento em que o capitalismo se prepara para ganhar força e as descrições que encontramos quase cem anos depois, quando a Grande Aceleração que vivemos agora já se fazia anunciar. Embora divididos entre sentimentos ambivalentes, os modernistas (alguns modernistas) foram os grandes entusiastas dessa beleza outra que a cidade indiscutivelmente nos proporciona. Mas, em 1976, numa obra colectiva que precisamente denunciava a transformação dos bens culturais em mercadorias, Joaquim Manuel Magalhães fazia esta constatação ambivalente: "Poucas vezes a beleza terá sido tanta / como nos lustros pretos dos sacos de lixo / à porta dos hotéis, dos armazéns, das casas de comida / nas mais pequenas 
horas da noite em Londres” (1976: s.p.). Essa beleza amarga, cujo brilho envolve os rejeitados, os tecidos contaminados por doenças, "tem um valor transformador do corpo / que o mata para esta vida”, conclui o poema, numa descrição que actualiza as palavras de Benjamin acerca da cidade de Baudelaire. E o poema de Joaquim Manuel Magalhães é absolutamente claro: o fascínio que exerce sobre nós a experiência urbana, com as suas formas artificiais de beleza contaminada pelo lixo que não conseguimos gerir, tem algo de mortífero que também precisamos de saber ver.

Enquanto leitor de Charles Baudelaire, Walter Benjamin observara que "no tipo ilustre do poeta, transparece um outro, vulgar, de que ele é cópia. O poeta é penetrado pelos traços do trapeiro, que tantas vezes ocupou Baudelaire”:

"Eis um homem cuja função é recolher o lixo de mais um dia na vida da capital. Tudo o que a grande cidade rejeitou, perdeu, partiu, é catalogado e coleccionado por ele. Vai compulsando os anais da devassidão, o cafarnaun da escória. Faz uma triagem, uma escolha inteligente; procede como um avarento com o seu tesouro, juntando o entulho que, entre as maxilas da deusa da indústria, voltaram a ganhar forma de objectos úteis ou agradáveis”. Esta descrição é apenas uma metáfora ampliada do trabalho do poeta segundo o sentimento de Baudelaire. Trapeiro ou poeta - a escória interessa a ambos; ambos exercem, solitários, a sua profissão, a horas em que os burgueses se entregam ao sono; até o gesto é o mesmo em ambos. (Benjamin 2006: 81)

Este olhar que incide sobre o fragmento constitui-se como a resposta possível à desagregação de um entendimento romântico da poesia, no qual inspiração e respiração deveriam coincidir no ritmo verbal enquanto ritmo da natureza, como podemos ver teorizado em Hölderlin e Schelling. Como imersão, portanto. Como superação da relação opositiva entre arte e natureza. Em The Theory of Inspiration, Thimothy Clark sintetiza de forma sugestiva o modo como, para Schelling, o artista objectiva na sua criação algo que o transcende e o unifica com o absoluto, já que é guiado "por um poder que o separa dos outros homens e o impele a dizer ou descrever coisas que não entende inteiramente, e cujo significado é infinito" (Schelling apud Clark 1997: 126). Por isso, o sentido da obra de arte nunca poderia ser inteiramente redutível a um sentido, dado que nele emergiria uma realidade transcendental, uma possibilidade de absoluto que excederia os limites da subjectividade. Hölderlin resumiu o desamparo do poeta enquanto subjectividade exposta à perda de limites decorrente da experiência de uma unidade infinita, ao reconhecer de maneira lapidar: "do mesmo modo que se cai para baixo, também se pode cair para cima” (Hölderlin apud Clark: 123).

Hoje talvez devêssemos aprender a cair com o mesmo entusiasmo, mas no preciso lugar onde estamos - chamemos-lhe mundo, Terra, lugar de imersão total, este 
que levamos dentro e fora de nós como o ar que respiramos -, deveríamos saber cair no exacto lugar onde estamos com o mesmo entusiasmo com que Hölderlin falou na possibilidade de se cair para cima. Ana Luísa Amaral disse isto mesmo de uma forma magnífica num dos ensaios de Arder a Palavra e outros incêndios:

O corpo não tem limites. Somos nós que a ele os impomos. Imaginamos que há no corpo linhas que o delimitam, mas, de facto, tal como tudo que existe no universo, o corpo é tangente a tudo e não existe num vácuo. As linhas do meu corpo são linhas imaginárias, porque o meu corpo se funde com o ar, invisível somente, mas matéria, assim como o meu corpo. Como o corpo do outro, ao meu lado. Assim poderão sempre os corpos tocar-se. No corpo paralelo ao biológico, inscreve-se a cultura e as suas formas simbólicas, ou seja, a arte e a poesia. (2017: 34)

É por esta ausência de limites que nos perderemos se não nos apercebermos dela a tempo e continuarmos a colocar arrogantemente o humano em condição de excepção no plano ontológico. Mas também é por ela que nos podemos salvar. E aqui, voltaria às propostas de André Barata, lembrando que quando este diz que o mais revolucionário talvez seja parar também chama a atenção para o facto de estarmos num tempo em que não podemos nem recuar nem avançar. Ou seja, se, por um lado, precisamos de recusar a fuga para frente (o mergulho suicidário na produção, justificado por uma espécie de fé cega na tecnologia, que tudo resolverá), por outro lado, também precisamos de recusar a ideia de que, para fugirmos à tirania do tempo acelerado, seria necessário suspender a produção e a tecnologia. "Parar não pode representar nem recuar nem avançar”, sustenta André Barata (2018: 107). De que se trata então? 0 seu livro ajuda-nos a identificar diferentes instâncias de dominação que concorrem para uma “concepção hegemónica do tempo" (idem: I08) que pode ser recusada nos nossos gestos do dia-a-dia, no trabalho, na vida. Em suma, trata-se de rever o uso que fazemos do tempo, ou melhor os usos que o tempo tem feito de nós, como André Barata bem sugere.

\section{$*$}

Para concluir, se bem que muito provisoriamente.

Quando Viveiros de Castro considera que os Yanomami são o futuro - e não o passado, como defendem aqueles que os querem "salvar" deles mesmos - dá-nos uma imagem para isto. Independentemente de todas as condições com que possamos argumentar, nós, seres humanos, não configuramos uma excepção ontológica, e menos ainda biológica; a nossa especificidade reflexiva não nos liberta da condição biológica partilhada que Emanuelle Coccia procura explicitar recorrendo à noção de imanência: 
A imanência não é mais a relação entre uma coisa e o mundo, ela é antes a relação que liga as coisas entre elas. É esta mesma relação que constitui o mundo. (...)

O facto de estar contido em alguma coisa coexiste com o facto de conter essa mesma coisa. (...) Essa identidade não é lógica, mas antes topológica e dinâmica. (2013: 104)

Eis, então, algumas sugestões para uma reflexão que supõe uma política, uma ética e uma poética. Os românticos, que captaram $a b$ ovo aquele dissídio essencial entre cultura e capitalismo que o capitalismo iria neutralizar pela transformação da cultura em mercadoria, elaboraram-nas escrupulosamente. Talvez possamos olhar de novo para o que escreveram e repensar a ideia de inspiração no que ela tem de proximidade a esta condição de "ser o que respiramos" de que fala Coccia, a esta condição de imanência que ao mesmo tempo nos excede e nos inclui. Talvez este seja um caminho para nos refazermos de há tantos anos nos querermos modernos.

\section{Notas}

* Rosa Maria Martelo é professora catedrática da Faculdade de Letras da Universidade do Porto onde lecciona Literatura Portuguesa e Estudos Interartes. Tem privilegiado o estudo de poesia e poéticas modernas e contemporâneas. Enquanto investigadora do Instituto de Literatura Comparada Margarida Losa interessam-lhe as ideações da imagem, particularmente os diálogos da poesia com as artes visuais e audiovisuais. Publicou alguns livros de poesia. Entre os mais recentes livros de ensaio contam-se O Cinema da Poesia (2a ed. 2017) e Os Nomes da Obra-Herberto Helder ou o Poema Contínuo (2016). Co-organizou a antologia Poemas com Cinema (Assírio \& Alvim, 2010) e organizou a Antologia Dialogante de Poesia Portuguesa (2020). Co-dirige a revista Elyra (www.elyra.org).

' Conferência proferida no âmbito do Colóquio Internacional Os Mil Nomes de Gaia - do Antropoceno à Idade da Terra, organizado por Eduardo Viveiros de Castro e Déborah Danowski no Rio de Janeiro entre 15 e 19 de setembro de 2014: <www.youtube.com/watch?v=CjbUıjO6rmE\&t=27s> (consultada em 2I de Março de 202I). 


\section{Bibliografia}

Amaral, Ana Luísa (2017), Arder a Palavra e outros incêndios, Lisboa, Relógio D’Água. Barata, André (2018), E se Parássemos de Sobreviver? Pequeno livro para pensar e agir contra a ditadura do tempo, Lisboa, Documenta.

Baudelaire, Charles (1976), “Exposition universelle (1855)”, CEuvres Complètes, vol. II, Paris, Gallimard, Bibliothèque de la Pléiade.

Benjamin, Walter (2006), A Modernidade, ed. e trad. de João Barrento, Lisboa, Assírio \& Alvim.

Castro, Eduardo Viveiros (2015), "Prefácio - o recado da mata”, in Kopenawa, Davi e Bruce Albert (2015), A Queda do Céu, Palavras de um xamã yanomami, trad. Beatriz Perrone-Moisés, São Paulo, Companhia das Letras, pp. II-43.

Clark, Timothy (1997), The Theory of Inspiration - Composition as a crisis of subjectivity in Romantic and post-Romantic writing, Manchester e Nova lorque, Manchester University Press.

Coccia, Emmanuelle (2019), A Vida das Plantas - Uma metafísica da mistura [2013], trad. Jorge Leandro Rosa, Lisboa, Fundação Carmona e Costa / Documenta.

Haraway, Donna (2015), “Anthropocene, Capitalocene, Plantationocene, Chthulucene”, Environmental Humanities, vol. 6, pp. 159-165.

Kopenawa, Davi e Bruce Albert (2015), A Queda do Céu, Palavras de Um Xamã Yanomami, trad. Beatriz Perrone-Moisés, São Paulo, Companhia das Letras.

Magalhães, Joaquim Manuel et alii (1976), [Cartucho], Lisboa, ed. autores.

Pessoa, Fernando (200I), Poesia [de Alberto Caeiro], edição de Fernando Cabral Martins e Richard Zenith, Lisboa, Assírio \& Alvim.

Scherer, Jacques (1977), Le «Livre» de Mallarmé, Paris, Gallimard.

Verde, Cesário (1880), [Nota sobre O Sentimento dum Ocidental] in Boletim do Centenário nO 2, Porto, Empresa do Jornal de Viagens, Maio, p. 27. 